\title{
Hot flashes: why?
}

\author{
Florica Sandru ${ }^{1,2}$, Mihai Cristian Dumitrascu ${ }^{1,3}$, Eugenia Petrova ${ }^{1,4}$, Anda Dumitrascu ${ }^{4}$, \\ Claudiu Tupea ${ }^{4}$, Mara Carsote ${ }^{1,4}$, Adina Ghemigian ${ }^{1,4}$, Ana Valea ${ }^{5,6}$ \\ 1"Carol Davila" University of Medicine and Pharmacy, Bucharest, Romania \\ 2Elias Emergency Hospital, Bucharest, Romania \\ 3University Emergency Hospital, Bucharest, Romania \\ 4"C.I. Parhon" National Institute of Endocrinology, Bucharest, Romania \\ 5"Iuliu Hatieganu" University of Medicine and Pharmacy, Cluj-Napoca, Romania \\ ${ }^{6}$ Clinical County Hospital, Cluj-Napoca, Romania
}

\begin{abstract}
Hot flashes (HF), transitory episodes of erythema, heat sensation, anxiety followed by chills, are described in carcinoid syndrome, mastocytosis, medullary thyroid cancer, hyperthyroidism, pheochromocytoma, alcohol consumption, side effects of drugs, and infections. They are pivotal among menopause-related vasomotor symptoms beside genitourinary syndrome in addition to sleep disturbances (40-60\% of females), and metabolic changes. HF affect $70 \%$ of women ( $20 \%$ of them have a severe impairment of life quality); they last for 4-7 years, starting 4-6 years before last menstruation. The main HF cause is ovarian-derivate estrogen deprivation which activates complex endocrine and neuroendocrine mechanisms involving noradrenaline, 5-hydroxytriptamine (5-HT), calcitonin gen-related peptide, orexin, kisspeptin, neurokinin B, and epigenetic elements like modulation of tachykinin receptor 3, accelerated epigenetic aging (as found in Women's Health Initiative Observational Study), expression of central serotonin transporters. Estrogen deficiency uncouples the negative feedback with preoptic area of hypothalamus, responsible for thermoregulation by inducing an exacerbated vasodilatory response to a small increase of body temperature. TRPV1 (transient receptor potential vanilloid 1) in preoptic hypothalamic area may play a role by NE- $\alpha 2 A D R$ (norepinephrine-activated $\alpha 2$-adrenergic receptors) activation. Higher expression of serotonin transporter SLC6A4 causes a lack of 5-HT at synapsis which is a trigger for presynaptic 5-HT receptor feedback, thus a release of serotonin amount prevents hot flashes. Kisspeptin and neurokinin B which are co-expressed in infundibular nucleus of hypothalamus are involved in central thermoregulation and gonadotropin releasing hormone anomalies. The NKR3 (neurokinin 3 receptor) antagonist receptor improves HF. Understanding the pivotal role of central neurotransmitters in hot flashes is the basis of new therapeutically researches because otherwise estrogen replacement has a long list of side effects, and it is contraindicated in breast cancer-related hypogonadism.
\end{abstract}

Keywords: hot flash, sweat, menopause, climacteric syndrome, vasomotor symptoms, estrogens, sleep, metabolic syndrome, serotonin, hypothalamus, thermoregulation, neurokinin $B$, norepinephrine

\section{INTRODUCTION}

Hot flashes, transitory episodes of erythema (from 1 minute to 5 minutes) in association with a sensation of heat, anxiety followed by chills, are described in different systemic conditions like neuroendocrine neoplasia-related carcinoid syndrome, mastocytosis, disseminated medullary thyroid cancer, emotion flushing, hyperthyroidism, pheochromocytoma and paraganglioma, alcohol-related flush, side effects to different drugs, food and beverages, infections etc. $(1,2)$. Menopause, lack of menstrual cycle for 12 consecutive cycles because of ovarian function loss, is accompanied by vasomotor symptoms like hot flashes (also called "night sweats", even they may also be presented during day time and many studies analyzed them separately), sleep anomalies, metabolic changes due to loss of ovarian estrogens production in addition to aging $(3,4)$. Despite multiple animal models studies, several mechanisms are still incompletely known (3) (Figure 1). 


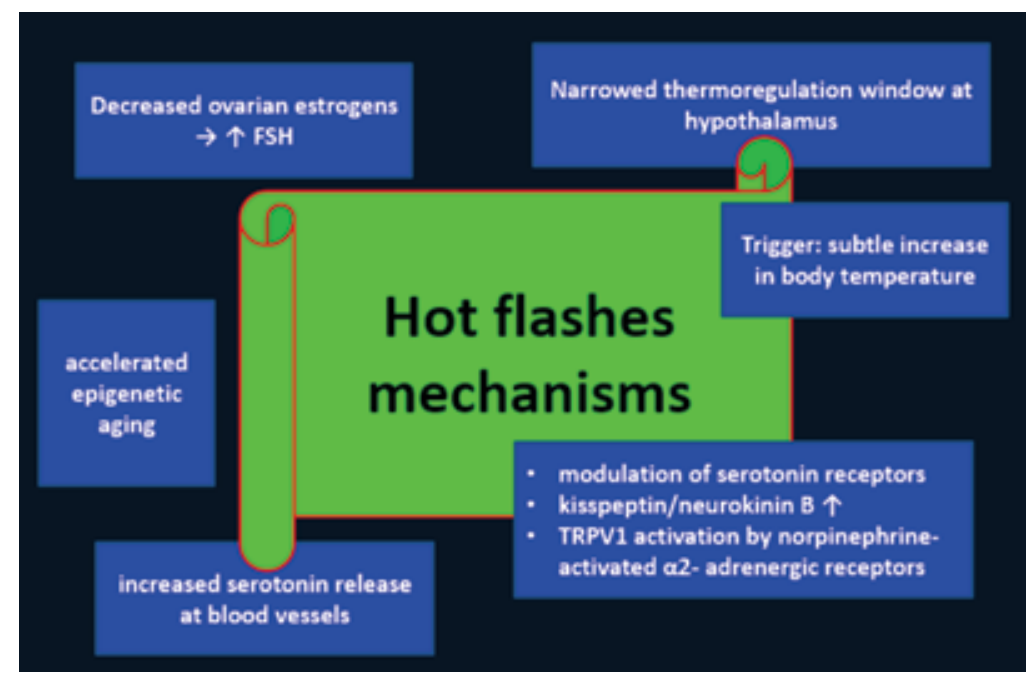

FIGURE 1. Different mechanisms related to hot flashes (see abbreviations and references in text)

Progressive decrease of estrogens is essential in understanding the vasomotor symptoms, vulvovaginal atrophy, and genitourinary syndrome of menopause (5). New data suggested that epigenetic aging may be a contributor element to vasomotor symptoms with late onset, as provided by genomic data on Women's Health Initiative Observational Study (6). Prior genome-wide association studies revealed 20 loci related to ovarian aging (7). A meta-analysis from 2020 showed based on 18 studies that 14 variant genes (out of 26 gene candidates) like CYP1B1 (cytochrome P450) and tachykinin receptor 3 (TACR3) gene are related to vasomotor symptoms (8). TACR3 study was first published in 2017 in women between 50 and 79 years that were enrolled in Women's Health Initiative Study (9).

\section{AIM}

We purpose a focus on mechanisms underlying hot flashes under menopausal conditions as major player in vasomotor symptoms constellation in addition to other anomalies.

\section{METHOD}

This is a narrative review. PubMed data was used for research (50 references were cited).

\section{RESULTS}

\section{Mechanisms of hot flashes}

Peri-menopausal period of time, namely menopausal transition, which includes 4-6 years before the actually stopping of menstruation, is accompa- nied by multiple symptoms and hot flashes represent the most frequent of them that may last for years $(70 \%$ of females experience hot flashes, with an average period of time for 4-7 years) and may severely damage the quality of life in $10-20 \%$ of women (10). Their presence is a turning point in medical approach, mainly the estrogen substitution, which is required for 4-5 years (and even longer in some cases) to control hot flashes and vaginal atrophy, respecting the principle of the lowest efficient dose on shortest period of time, with progesterone association if uterus is present (11).

Hot flashes underline complex endocrine, epigenetic and neuroendocrine mechanisms; kisspeptin, neurokinin B, noradrenaline, 5-hydroxytriptamine (5-HT), calcitonin gen-related peptide are involved (12-14). Estrogen deficiency uncouple the negative feedback with hypothalamus; dysfunction of hypothalamic thermoregulation consists in a exacerbated vasodilatory response to a small increase of body temperature (a narrowed window of thermoregulation) $(12,14)$. Hypothalamic regulation of body temperature affects preoptic area where different neurotransmitters and their receptors play a role in heat resumption (15). Recently, a murine experiment described TRPV1 (transient receptor potential vanilloid 1) in preoptic hypothalamic area with a role in hot flashes-related abnormal thermoregulation; TRPV1 being activated by NE- $\alpha 2$ ADR (norepinephrine-activated $\alpha 2$-adrenergic receptors), which are situated at the level of dorsal root ganglia (15). Other rodent studies showed a role of orexin in anxiety and thermoregulation (16). The neuropeptide is synthetized at the level of perifornical hypothalamus and it is inhibited by estrogen receptors, thus meno- 
pause-related estrogen deprivation increases its central levels with consecutive exacerbation of hot flashes and anxiety (17). Moreover, murine models reproduce the skin temperature changes that mimic hot flushes in ovarectomized rats; recently, the idea that different areas of teguments differently respond to the ovarian status was suggested in these experiments (18). When it comes to central regulation of body temperature, serotonin also plays a role, including epigenetic regulation of serotonin transporters (19). For instance, higher expression of SLC6A4 (as revealed by microRNA studies) causes a serotonin lack at the level of synapsis which is a trigger for presynaptic 5-HT receptor feedback, thus a release of serotonin amount is present preventing the hot flashes (20). Severe phenotype of hot flashes is not correlated with cortisol and testosterone levels at the level of blood but with low estrogen, and increased FSH (follicle stimulant hormone) or decreased epinephrine/increased norepinephrine values; hypothalamic - pituitary - ovarian axes assays (estrogen/FSH) might serve as biomarkers of symptoms severity, as found in Seattle Midlife Women's Health Study (21). Vascular reactivity that causes the skin anomalies is related to adrenergic system (norepinephrine is more important that epinephrine) (22). But with respect to reducing the window of brain thermoregulation, estrogen/FSH are less important than central neurotransmitters like serotonin and epinephrine (23). During menopause transition, hypothalamus integrates both gonadotropin releasing hormones $(\mathrm{GnRH})$ and thermoregulation via central neuropeptides like kisspeptin and neurokinin B, which are expressed in its neurons (infundibular nucleus) (24). In subjects with vasomotor symptoms, kisspeptin/neurokinin B are over-expressed opposite to dynorphin which is downregulated, while experimental administration of NK3R (neurokinin B receptor 3) agonists like senktide induces hot flashes, tachycardia, high skin temperature $(25,26)$.

\section{Hot flashes - associated elements}

Sleep anomalies accompany menopausal transition in $40-60 \%$ of females which is more frequent than during prior reproductive years, especially in women with general sleep disturbances, co-presence of anxiety and depression, familial pattern of having a certain cluster of sleep disturbances like insomnia, etc., phyco-social modulators (for instance, chronic alcohol consumption, marital/familial and professional dissatisfactions), and the presence of additional medical risk factors/condi- tions like urinary anomalies, organic pain during the night influencing the sleep phases (as restless legs syndrome, joints, muscles and bones chronic pain, variations of blood pressure levels with associated headache during the presence of extreme high or low values) (27). A list of conditions that impair sleep during menopausal period of time include obesity, gastroesophageal reflux, different types of cancers, uncontrolled hyperthyroidism; also fibromyalgia has been reported to onset and aggravate during this period $(28,29)$. "Domino hypothesis" has been suggested when describing the relationship between hot flashes and sleep anomalies, meaning that hot flashes aggravate the abnormal sleep while lack of adequate sleep decreases the threshold for hot flashes or may aggravate the depression (30). Moreover, hot flashes-related insomnia involves a constant hyperarousal, both before sleep time and all along during the day time (31).

Depending the severity of vasomotor symptoms, insomnia may be similarly treated as these symptoms (for instance, estrogens for subjects with severe hot flashes) or it may approached based on cognitive behavioral therapy, antidepressants if depression is associated, paroxetine or oral melatonin (like prolonged-released formula with a good tolerance, being preferred in women over 55 years) (27). Therapy with transdermal estradiol and intermittent progesterone to control vasomotor symptoms showed that their improvement (including hot flashes and depressive elements) does not entirely control the sleep profile, probably because of the fact that some other mechanisms are actually involved during peri-menopause (32). On the other way, if sleep disturbances are not controlled, the mentioned associated diseases, which are potential additional factors to poor quality sleep, may aggravate; supplementary deterioration for cardiovascular status and obstructive sleep apnea syndrome have been suggested (33). Also, worsening of insulin resistance and onset of non-alcoholic fatty liver disease is described (34). Traditional explanation for increased cardiovascular risk in females with hot flashes is dysfunction of stress response under physiological conditions (35).

Another potential associated element of vasomotor symptoms is reduced memory capacity as reflected by executing a verbal memory task, probably due to estrogen deficiency-related effects on brain, mainly hippocampus and prefrontal cortex (36). Functional magnetic resonance imaging studies confirmed these aspects (37). Overall, sleep, mood and cognitive (so call "brain fog") troubles have a major impact on quality of life (38). 
Progressive estrogens deprivation may also cause hot-flashes accompanied metabolic dysfunctions like increased abdominal fat, dyslipidemia, arterial hypertension (39). One study from 2020 showed a statistically significant correlation between hot flashes and metabolic syndrome in women over 40 years (39). Weight control (meaning weight loss in females with increased body mass index) during menopausal transition might be a double hit for both controlling the hot flashes and metabolic anomalies, although hot flashes equally affect normal weighted women (40). For instance, Midlife Women's Health Study (a longitudinal trial between 2006 and 2015 that included 780 females, follow-up for 4-7 years, aged between 45 and 54 years) showed that body mass index is not correlated with hot flashes instead older age at menopause, peri-menopausal status, current smoker status, lower estrogens/progesterone values and co-presence of depressive symptoms are correlated with the presence of hot flashes (41). Other studies found that high frequency of hot flashes is correlated with endothelial dysfunction (42). A pool analysis published on 2021 included 18,555 females InterLACE (International collaboration on the Life course Approach to reproductive health and Chronic disease Events) data showed that early menarche age (prior to the age of 14 years) is associated with severe vasomotor symptoms (increased risk of both hot flashes and night sweats), but if the females were obese or over weighted during midlife in addition to early menarche, the menopausal symptoms are even more severe (43).

Conflict of interest: none declared

Financial support: none declared

\section{REFERENCES}

1. Iliesiu A, Ungureanu IA, Petca A, Constantin MM, Petca RC, Sandru $\mathrm{F}$, Constantin T, Dumitrascu MC. Paraganglioma presenting as a mesenteric cystic mass: A case report. Exp Ther Med. 2020 Sep;20(3):2489-2492.

2. Miulescu R, Balaban DV, Sandru F, Jinga M. Cutaneous Manifestations in Pancreatic Diseases-A Review. J Clin Med. 2020 Aug 12;9(8):2611.

3. Yin W, Borniger JC, Wang X, Maguire SM, Munselle ML, Bezner KS, Tesfamariam HM, Garcia AN, Hofmann HA, Nelson RJ, Gore AC. Estradiol treatment improves biological rhythms in a preclinical rat model of menopause. Neurobiol Aging. 2019 Nov;83:1-10.

4. Bain J, Bragg S, Ramsetty A, Bradford S. Endocrine Conditions in Older Adults: Menopause. FP Essent. 2018 Nov;474:20-27.

5. Nappi RE, Di Carlo C, Cucinella L, Gambacciani M. Viewing symptoms associated with Vulvovaginal Atrophy (VVA)/Genitourinary syndrome of menopause (GSM) through the estro-androgenic lens Cluster analysis of a web-based Italian survey among women over 40. Maturitas. 2020 Oct; $140: 72-79$.

6. Thurston RC, Carroll JE, Levine M, Chang Y, Crandall C, Manson JE, Pal L, Hou L, Shadyab AH, Horvath S. Vasomotor Symptoms and Accelerated Epigenetic Aging in the Women's Health Initiative (WHI). $J$ Clin Endocrinol Metab. 2020 Apr 1;105(4):1221-7.

\section{DISCUSSIONS}

Future medications are under development to address the central regulatory pathways against hot flashes, knowing that currently SSRI (selective serotonin reuptake inhibitors) are approved for vasomotor symptoms control especially in patients with contraindications to estrogens like survivals of mammary cancer $(44,45)$. Antagonists of NK3R act at thermoregulation hypothalamic centrum to improve the pattern of vasomotor symptoms (44). Antagonists of neurokinin/NKR3 have proven clinical efficacy in both controlling the hot flashes and associated sleep anomalies $(45,46)$. The improvement of GnRH levels under medication confirms the role of neurokinin 3 in menopause-associated symptoms while kisspeptin levels are not modified, probably because they are under direct influence of hypoestrogenic status $(47,48)$. As an extension of kisspeptin (and its receptor Kiss-1) neurokinin B complex signaling pathway, we mention the other end of the spectrum: their agonists used as ovulation inductors, for instance, in polycystic ovary syndrome or in controlling hypothalamic amenorrhea and delayed puberty $(49,50)$.

\section{CONCLUSION}

Understanding the pivotal role of central neurotransmitters in hot flashes is the basis of new therapeutically researches because estrogen replacement has a long list of side effects, and it is contraindicated in breast cancer-related hypogonadism.
7. Wood MA, Rajkovic A. Genomic markers of ovarian reserve. Semin Reprod Med. 2013 Nov;31(6):399-415.

8. Crandall CJ, Diamant AL, Maglione M, Thurston RC, Sinsheimer J. Genetic Variation and Hot Flashes: A Systematic Review. J Clin Endocrinol Metab. 2020 Dec 1;105(12):e4907-57.

9. Crandall CJ, Manson JE, Hohensee C, Horvath S, Wactawski-Wende J, LeBlanc ES, Vitolins MZ, Nassir R, Sinsheimer JS.Me Association of genetic variation in the tachykinin receptor 3 locus with hot flashes and night sweats in the Women's Health Initiative Study. Menopause. 2017 Mar;24(3):252-261.

10. Martin KA, Manson JE. Approach to the patient with menopausal symptoms. J Clin Endocrinol Metab. 2008 Dec;93(12):4567-75.

11. Hill DA, Crider M, Hill SR. Hormone Therapy and Other Treatments for Symptoms of Menopause. Am Fam Physician. 2016 Dec 1;94(11):884-889.

12. Vilar-González S, Pérez-Rozos A, Cabanillas-Farpón R. Mechanism of hot flashes. Clin Transl Oncol. 2011 Mar;13(3):143-7.

13. Poiana C, Musat M, Carsote M, Chirita C. Premenstrual dysphoric disorder: neuroendocrine interferences. Rev Med Chir Soc Med Nat (lasi). 2009 Oct-Dec;113(4):996-1000.

14. Bansal R, Aggarwal N. Menopausal Hot Flashes: A Concise Review. J Midlife Health. 2019 Jan-Mar;10(1):6-13. 
15. Sun Y, Wang W, Zhou C, Ma X, Bai W, Zhang J, Yang Q, Wang K, Jia J, Liu G, Qin L. Changes in TRPV1 expression in the POA of ovariectomized rats regulated by NE-dependent alpha2-ADR may be involved in hot flashes. Ann Anat. 2020 Nov;232:151565.

16. Federici LM, Roth SD, Krier C, Fitz SD, Skaar T, Shekhar A, Carpenter JS, Johnson PL. Anxiogenic CO2 stimulus elicits exacerbated hot flash-like responses in a rat menopause model and hot flashes in postmenopausal women. Menopause. 2016 Nov;23(11):1257-1266.

17. Federici LM, Caliman IF, Molosh AI, Fitz SD, Truitt WA, Bonaventure P, Carpenter JS, Shekhar A, Johnson PL. Hypothalamic orexin's role in exacerbated cutaneous vasodilation responses to an anxiogenic stimulus in a surgical menopause model. Psychoneuroendocrinology. 2016 Mar;65:127-37.

18. Sun Y, Yang Q, Bai W, Wang W, Li Y, Luo X, Wang S, Jia J, Wang K, Qin L. Changes in skin temperature of ovariectomized rats under different incubation temperatures. Geriatr Gerontol Int. 2020 Jun;20(6):621-628.

19. lurescia S, Seripa D, Rinaldi M. Looking Beyond the 5-HTTLPR Polymorphism: Genetic and Epigenetic Layers of Regulation Affecting the Serotonin Transporter Gene Expression. Mol Neurobiol. 2017 Dec;54(10):8386-8403.

20. Montasser ME, Ziv-Gal A, Brown JP, Flaws JA, Merchenthaler I. A potentially functional variant in the serotonin transporter gene is associated with premenopausal and perimenopausal hot flashes. Menopause. 2015 Jan;22(1):108-13.

21. Woods NF, Cray L, Mitchell ES, Herting JR. Endocrine biomarkers and symptom clusters during the menopausal transition and early postmenopause: observations from the Seattle Midlife Women's Health Study. Menopause. 2014 Jun;21(6):646-52.

22. Sassarini J, Fox H, Ferrell W, Sattar N, Lumsden MA. Hot flushes, vascular reactivity and the role of the alpha-adrenergic system. Climacteric. 2012 Aug;15(4):332-8.

23. Archer DF, Sturdee DW, Baber R, de Villiers TJ, Pines A, Freedman RR, Gompel A, Hickey M, Hunter MS, Lobo RA, Lumsden MA, MacLennan AH, Maki P, Palacios S, Shah D, Villaseca P, Warren M. Menopausal hot flushes and night sweats: where are we now? Climacteric. 2011 Oct;14(5):515-28.

24. Anderson RA, Skorupskaite K, Sassarini J. The neurokinin B pathway in the treatment of menopausal hot flushes. Climacteric. 2019 Feb;22(1):51-54.

25. Rance NE, Dacks PA, Mittelman-Smith MA, Romanovsky AA, Krajewski-Hall SJ. Modulation of body temperature and LH secretion by hypothalamic KNDy (kisspeptin, neurokinin B and dynorphin) neurons: a novel hypothesis on the mechanism of hot flushes. Front Neuroendocrinol. 2013 Aug;34(3):211-27.

26. Szeliga A, Czyzyk A, Podfigurna A, Genazzani AR, Genazzani AD, Meczekalski B. The role of kisspeptin/neurokinin B/dynorphin neurons in pathomechanism of vasomotor symptoms in postmenopausal women: from physiology to potential therapeutic applications. Gynecol Endocrinol. 2018 Nov;34(11):913-919.

27. Proserpio P, Marra S, Campana C, Agostoni EC, Palagini L, Nobili L, Nappi RE. Insomnia and menopause: a narrative review on mechanisms and treatments. Climacteric. 2020 Dec;23(6):539-549.

28. Dumitrascu MC, Stanescu AMA, Bejan C, Sandru F, Toader DO, Radavoi DG, Cotirlet A, Judea Pusta CT, Diaconu CC. Obesity and its implications on stress urinary incontinence. Revista de Chimie. 2019;70(10):3660-2.

29. Caretto M, Giannini A, Simoncini T. An integrated approach to diagnosing and managing sleep disorders in menopausal women. Maturitas. 2019 Oct:128:1-3.

30. Bonanni E, Schirru A, Di Perri MC, Bonuccelli U, Maestri M. Insomnia and hot flashes. Maturitas. 2019 Aug;126:51-54.

31. Bertisch SM, Wiley A, McCormick K, Muresan C, Camuso J, Albert K, Crawford SL, Newhouse P, Taylor JA, Joffe H. Cardiovascular reactivity and psychological hyperarousal in hot flash-associated insomnia disorder. Menopause. $2019 \mathrm{Jul} ; 26(7): 728-740$.

32. Geiger PJ, Eisenlohr-Moul T, Gordon JL, Rubinow DR, Girdler SS. Effects of perimenopausal transdermal estradiol on self-reported sleep, independent of its effect on vasomotor symptom bother and depressive symptoms. Menopause. 2019 Nov;26(11):1318-1323.
33. Baker FC, Willoughby AR, Sassoon SA, Colrain IM, de Zambotti M. Insomnia in women approaching menopause: Beyond perception. Psychoneuroendocrinology. 2015 Oct;60:96-104.

34. Ryu KJ, Park H, Kim YJ, Yi KW, Shin JH, Hur JY, Kim T. Moderate to severe vasomotor symptoms are risk factors for non-alcoholic fatty liver disease in postmenopausal women. Maturitas. 2018 Nov; 117:22-28.

35. Gordon JL, Rubinow DR, Thurston RC, Paulson J, Schmidt PJ, Girdler SS. Cardiovascular, hemodynamic, neuroendocrine, and inflammatory markers in women with and without vasomotor symptoms. Menopause. 2016 Nov;23(11):1189-1198.

36. Maki PM, Wu M, Rubin LH, Fornelli D, Drogos LL, Geller S, Shulman LP, Banuvar S, Little DM, Conant RJ. Hot flashes are associated with altered brain function during a memory task. Menopause. 2020 Mar;27(3):269-277.

37. Fogel J, Rubin LH, Kilic E, Walega DR, Maki PM. Physiologic vasomotor symptoms are associated with verbal memory dysfunction in breast cancer survivors. Menopause. 2020 Nov;27(11):1209-1219.

38. Gava G, Orsili I, Alvisi S, Mancini I, Seracchioli R, Meriggiola MC. Cognition, Mood and Sleep in Menopausal Transition: The Role of Menopause Hormone Therapy. Medicina (Kaunas). 2019 Oct 1;55(10):668.

39. Saú HPF, Schmitt ACB, Cardoso MRA, Aldrighi JM. Prevalence of hot flashes in women of 40 to 65 years of age with metabolic syndrome. Rev Assoc Med Bras (1992). 2020 Dec;66(12):16281632.

40. Shulman LP. An intervention to reduce vasomotor symptoms and induce weight loss at the menopause transition: can we really get two for the price of one? Menopause. 2020 Nov;27(11):1207-1208.

41. Ziv-Gal A, Smith RL, Gallicchio L, Miller SR, Zacur HA, Flaws JA. The Midlife Women's Health Study - a study protocol of a longitudinal prospective study on predictors of menopausal hot flashes. Womens Midlife Health. 2017 Aug 17;3:4.

42. Thurston RC, Chang Y, Barinas-Mitchell E, Jennings JR, von Känel $\mathrm{R}$, Landsittel DP, Matthews KA. Physiologically assessed hot flashes and endothelial function among midlife women. Menopause. 2017 Aug;24(8):886-893.

43. Chung HF, Zhu D, Dobson AJ, Kuh D, Gold EB, Crawford SL, Avis NE, Mitchell ES, Woods NF, Anderson DJ, Mishra GD. Age at menarche and risk of vasomotor menopausal symptoms: a pooled analysis of six studies. BJOG. $2021 \mathrm{Feb} ; 128(3): 603-613$.

44. Modi M, Dhillo WS. Neurokinin 3 Receptor Antagonism: A Novel Treatment for Menopausal Hot Flushes. Neuroendocrinology. 2019;109(3):242-248.

45. Modi M, Dhillo WS. Neurokinin B and Neurokinin-3 Receptor Signaling: Promising Developments in the Management of Menopausal Hot Flushes. Semin Reprod Med. 2019 May; 37(3):125-130.

46. Prague JK, Roberts RE, Comninos AN, Clarke S, Jayasena CN, Nash Z, Doyle C, Papadopoulou DA, Bloom SR, Mohideen P, Panay N, Hunter MS, Veldhuis JD, Webber LC, Huson L, Dhillo WS. Neurokinin 3 receptor antagonism as a novel treatment for menopausal hot flushes: a phase 2, randomised, double-blind, placebo-controlled trial. Lancet. 2017 May 6;389(10081):1809-1820.

47. Skorupskaite K, George JT, Veldhuis JD, Millar RP, Anderson RA. Neurokinin 3 Receptor Antagonism Reveals Roles for Neurokinin B in the Regulation of Gonadotropin Secretion and Hot Flashes in Postmenopausal Women. Neuroendocrinology. 2018; 106(2):148-157.

48. Prague JK, Dhillo WS. Neurokinin 3 receptor antagonism - the magic bullet for hot flushes? Climacteric. 2017 Dec;20(6):505-509.

49. Szeliga A, Podfigurna A, Bala G, Meczekalski B. Kisspeptin and neurokinin $B$ analogs use in gynecological endocrinology: where do we stand? J Endocrinol Invest. 2020 May;43(5):555-561.

50. Qi X, Salem M, Zhou W, Sato-Shimizu M, Ye G, Smitz J, Peng C. Neurokinin B Exerts Direct Effects on the Ovary to Stimulate Estradiol Production. Endocrinology. 2016 Sep;157(9):3355-65. 